\title{
Erilaisten työkonerenkaiden aiheuttamat muutokset peltomaassa
}

\author{
Juhani Kurjenluoma ${ }^{1)}$, Jukka Ahokas ${ }^{1)}$, Laura Alakukku ${ }^{2)}$ \\ ${ }^{1)}$ Helsingin yliopisto, Agroteknologian laitos, 00014 Helsingin yliopisto, PL 28 Koetilantie 3, \\ juhani.kurjenluoma@helsinki.fi,jukka.ahokas@helsinki.fi \\ ${ }^{2)}$ Maa- ja elintarviketalouden tutkimuskeskus, Maaperä ja ympäristö, 31600 Jokioinen, lau- \\ ra.alakukku@mtt.fi
}

\section{Tiivistelmä}

Raskas peltoliikenne on lisääntynyt merkittävästi maatalouden koneellistumisen myötä. Kokonaismassaltaan yli 30 t koneet eivät enää ole harvinaisia. Renkaasta maahan välittyvä kuorma aiheuttaa maan huokos- ja mururakenteen rikkoutumista sekä muokkauskerroksessa että sen alapuolella olevassa pohjamaassa. Muutokset voivat olla pitkäaikaisia ja ne voivat haitata maan viljelyä, pienentää satoa sekä lisätä peltoviljelyn ympäristökuormitusta. Maassa tapahtuviin muutoksiin vaikuttavat maan ominaisuuksien ja yksittäisten koneiden ohella käytettävät työmenetelmät ja koneketjut sekä töiden ajoitus ja niitä voidaan vähentää minimoimalla peltoliikenne, käyttämällä olosuhteisiin parhaiten soveltuvaa teknologiaa sekä oikeaa rengasvarustusta.

Renkaan pintapaineen ylittäessä maan kantavuuden rengas alkaa upota ja maan pintakerros tiivistyy. Rengaskuorman kasvaessa sen tiivistävä vaikutus ulottuu myös maan syvempiin kerroksiin. Renkaan uppoutumista ja siitä aiheutuvaa vetovastusta voidaan vähentää alentamalla rengaspainetta, pienentämällä kuormaa, lisäämällä renkaan kokoa ja käyttämällä vyörenkaita. Maan rakennevaurioiden välttämiseksi on tunnettava erityyppisten renkaiden ominaisuudet ja maan tiivistymisherkkyys.

Tässä tutkimuksessa selvitettiin kahden vyörenkaan ja yhden ristikudosrenkaan vaikutusta savimaan penetrometrivastukseen. Renkaiden koko oli 600/55-26.5. Rengaskuorma oli 3,7 Mg ja käytetyt paineet $100 \mathrm{kPa}$ renkaalla $1,120 \mathrm{kPa}$ ja $200 \mathrm{kPa}$ renkaalla 2 ja $200 \mathrm{kPa}$ renkaalla 3. Rengaspaine mitoitettiin valmistajan tai maahantuojan ohjeiden mukaan sekä pelto- tai maantieajoon sopivaksi käytetyn rengaskuorman mukaisesti. Vertailu tehtiin ajamalla muokatulla pellolla ja mittaamalla maan tunkeumapaine (cone-indeksi) penetrometrillä renkaan urasta ja vertaamalla sitä tiivistämättömästä maasta mitattuihin arvoihin. Mittaukset tehtiin heti ajon jälkeen sekä seuraavan vuoden keväällä.

Mittausten mukaan kerta-ajosta maan 0-15 cm pintakerros oli tiivistynyt. Vyörenkaalla korkea rengaspaine aiheutti muita renkaita selvästi voimakkaampaa tiivistymistä, joka oli mitattavissa vuoden kuluttua ajosta. Suuri rengaspaine pienentää maan ja renkaan välistä kosketusalaa vyörenkaalla ja pintapaine aiheuttaa maan pakkautumisen pehmeissä olosuhteissa.

Asiasanat: työkonerengas, vyörengas, ristikudosrengas, tiivistyminen, rengaskuorma, rengaspaine, pintapaine, peltopaine, tiepaine, cone-indeksi, 


\section{Johdanto}

Raskas peltoliikenne on lisääntynyt merkittävästi maatalouden tehokkuuden kasvun myötä. Kokonaismassaltaan yli 30 t lannanlevittimet, rehuvanut sekä korjuukoneet eivät ole harvinaisia ja niiden rengaspaineet ovat peltokäyttöön korkeita, $300-400 \mathrm{kPa}$. Renkaan ja maan välisen kosketuspinnan kautta pintapaineena välittyvä kuorma voi rikkoa maan huokos- ja mururakenteen sekä muokkauskerroksessa että sen alapuolella olevassa pohjamaassa. Pohjamaassa muutokset ovat pitkäaikaisia (Alakukku 2000) ja ne voivat haitata viljelyä, pienentää satoa sekä lisätä peltoviljelyn ympäristökuormitusta muuttaessaan veden ja ravinteiden kulkua. Maan rakennemuutoksiin vaikuttavat maan ominaisuuksien ja yksittäisten koneiden ohella käytettävät työmenetelmät ja koneketjut sekä töiden ajoitus. Maassa tapahtuvia muutoksia voidaan vähentää minimoimalla peltoliikenne maan ollessa märkää, käyttämällä olosuhteisiin parhaiten soveltuvaa teknologiaa sekä oikeaa rengasvarustusta. Renkaan pintapaineen ylittäessä maan kantavuuden maan pintakerros tiivistyy ja rengas alkaa upota. Rengaskuorman kasvaessa renkaan tiivistävä vaikutus ulottuu maassa entistä syvemmälle ja pohjamaan tiivistymisriski on suuri (Alakukku ym. 2003). Renkaan uppoutumista ja siitä aiheutuvaa vetovastusta voidaan vähentää alentamalla rengaspainetta, pienentämällä kuormaa, lisäämällä rankaan kokoa ja käyttämällä vyörenkaita (McAllister 1983). Maan rakennevaurioiden välttämiseksi on tunnettava erityyppisten renkaiden tiivistämisominaisuudet ja maan tiivistymisherkkyys. Tietoa rengaskuorman ja paineen vaikutuksesta maan tiivistymiseen sekä keinoista sen välttämiseksi tarvitaan lisää (Chamen ym. 2003).

Peltoajossa rengaspaine ja käytettävien renkaiden ominaisuudet, kudosrakenne ja elastisuus, vaikuttavat maan ja renkaan väliseen kosketuspinnan alaan sekä rengaskuormasta maahan kohdistuvaan pintapaineeseen ja sen jakautumiseen niin kosketuspinnan alalle kuin syvyyssuunnassakin. Eri renkaiden maata tiivistävissä ominaisuuksissa on ollut mitattavia eroja (McAllister 1983). Oikealla rengasvalinnalla voidaan vähentää peltoliikenteen haittavaikutuksia maahan.

Useimmissa hankkeissa, joissa on selvitetty renkaiden ominaisuuksien vaikutusta maan tiivistymiseen, on tutkittu vetokoneen renkaita. Traktoria käytetään käytännössä kaikissa peltoviljelytöissä. Håkansson (2005) laski, että tavanomaisessa viljanviljelyssä, jossa maa kynnetään, vuotuisessa peltoajossa traktorin pyöränjälkien yhteenlaskettu ala peittää pellon pinnan alan vähintään kerran. Työkoneiden renkaiden jättämien urien peittävyys on yleensä edellistä pienempi. Kun peltotöissä on paljon kuljetus- ja siirtoajoa, kuten lannan levityksessä ja säilörehun korjuussa, työkoneiden pyöränjälkien peittävyys pellon pinnan alasta on merkittävä. Peltotöissä käytettävien työkoneiden renkaiden ominaisuuksiin on kiinnitetty kuitenkin yleensä vähän huomiota ja niiden vaikutusta maan tiivistymiseen on tutkittu harvoin.

Tässä tutkimuksessa selvitettiin työkonerenkaiden ominaisuuksien vaikutusta savimaan tiivistymiseen. Siinä tutkittiin, miten vedettävän renkaan rakenne ja rengaspaine vaikuttavat maan penetrometrivastukseen ja huokostoon. Tässä julkaisussa käsitellään penetrometrivastustuloksia.

\section{Aineisto ja menetelmät}

Mittaukset tehtiin MTT/Vakolan pellolla Vihdissä keväällä 2003. Edellisenä syksynä kynnetty savimaa äestettiin kertaalleen ennen koetta tasausäkeellä $\mathrm{n} .6 \mathrm{~cm}$ syvyyteen, minkä jälkeen vertailussa olevilla renkailla ajettiin urat (2/ruutu) kolmeen, arvotussa järjestyksessä sijainneisiin koealoihin. Vertailtavat renkaat olivat kooltaan 600/55-26.5. Rengaskuorma oli 3,7 Mg ja käytetyt rengaspaineet $100 \mathrm{kPa}$ renkaalla $1,120 \mathrm{kPa}$ ja $200 \mathrm{kPa}$ renkaalla 2 ja $200 \mathrm{kPa}$ renkaalla 3 (taulukko 1). Rengaspaine mitoitettiin valmistajan tai maahantuojan ohjeiden mukaan sekä pelto- tai maantieajoon sopivaksi käytetyn rengaskuorman mukaisesti. Renkaat asennettiin 1-akseliseen perävaunuun, joka voitiin painottaa betonipainoin halutun rengaskuorman aikaansaamiseksi. Perävaunu kytkettiin vetotraktoriin epäkeskisesti apurungon avulla, jolloin perävaunun pyörät tekivät urat muokattuun maahan.

Renkaiden vaikutus maahan selvitettiin mittaamalla maan tunkeumapaine eli cone-indeksi (CI) ASAE standardin S313.3 FEB99 mukaisesti Eijelkamp 06.15 penetrometrillä, jonka kartiokulma oli 30 astetta ja ala $1,8 \mathrm{~cm}^{2}$. Mittaukset tehtiin renkaan urasta sekä äestetystä maasta. Mittaukset tehtiin kohtisuorassa linjassa uran suhteen $10 \mathrm{~cm}$ välein rei'itettyä mittalankkua apuna käyttäen. Jokaisesta 
Taulukko 1. Vertailtavat renkaat ja käytetyt rengaspaineet

\begin{tabular}{lrrr}
\hline & & 2 & \\
& $600 / 55 R 26.5$ & $600 / 55 R 26.5$ & $600 / 55-26.5$ \\
\end{tabular}

urasta tehtiin 10 mittausta. Äestetyistä verrannealoista (3 kpl) tehtiin kaksi 10 mittauksen sarjaa jokaisesta. Mittaukset ulottuivat $60 \mathrm{~cm}: n$ syvyyteen ja penetrometri tallensi mittaustuloksen $1 \mathrm{~cm}: n$ välein syvyyssuunnassa. Mittauksia tehtiin kaksi, ensimmäinen välittömästi urien ajon jälkeen ja toinen vuoden kuluttua ajosta. Lisäksi tutkittiin maan huokoisuus jokaisesta urasta syksyllä 2003 otetuista näytteistä. Maan huokoisuustulokset esitetään myöhemmin ja tässä esitellään penetrometrivastusmittausten alustavia tuloksia.

Penetrometrin tallentamat mittaustulokset analysoitiin Exel- ja SPSS laskentaohjelmilla. Renkaiden maata tiivistävä vaikutus selvitettiin vertaamalla mittaustuloksista laskettuja keskiarvoja keskenään sekä vertaamalla niitä häiriintymättömän maan tuloksiin. Eri renkaiden pellon pintakerrosta tiivistävää ominaisuutta selvitettiin laskemalla tunkeumapaine maan pinnasta $15 \mathrm{~cm}$ syvyyteen ja vertaamalla eri mittauksista saatuja tuloksia keskenään sekä verranne maasta saatuihin tuloksiin.

\section{Tulokset ja tulosten tarkastelu}

Tulosten mukaan maa oli tiivistynyt peltoajon vaikutuksesta 5-20 cm:n kerroksessa (kuva 1). Heti ajon jälkeen voimakkain tiivistymä mitattiin $\mathrm{n} .5 \mathrm{~cm}$ ajouran alapuolella $5-15 \mathrm{~cm}: n$ kerroksessa (kuva 1, mittaus A). Tämä tukee aiempia tuloksia, joiden mukaan tiivistyminen on voimakkainta vähän ajouran alapuolella aina $25 \mathrm{~cm}: n$ asti ja riippuu ensisijaisesti renkaiden maahan aiheuttamasta pintapaineesta (Alakukku ym. 1995, Kulli ym. 2003). Välittömästi ajon jälkeen mitatuissa tuloksissa renkaiden välillä ei ole havaittavissa merkittäviä eroja, sen sijaan vuoden kuluttua (kuva 1, mittaus B) eroja renkaiden välillä on. Suuren rengaspaineen vaikutus näkyy selvästi vyörenkaan tuloksessa. Eri mittausten välinen tasoero johtuu eri mittausajankohtina olleista eroista maan kosteusoloissa. 

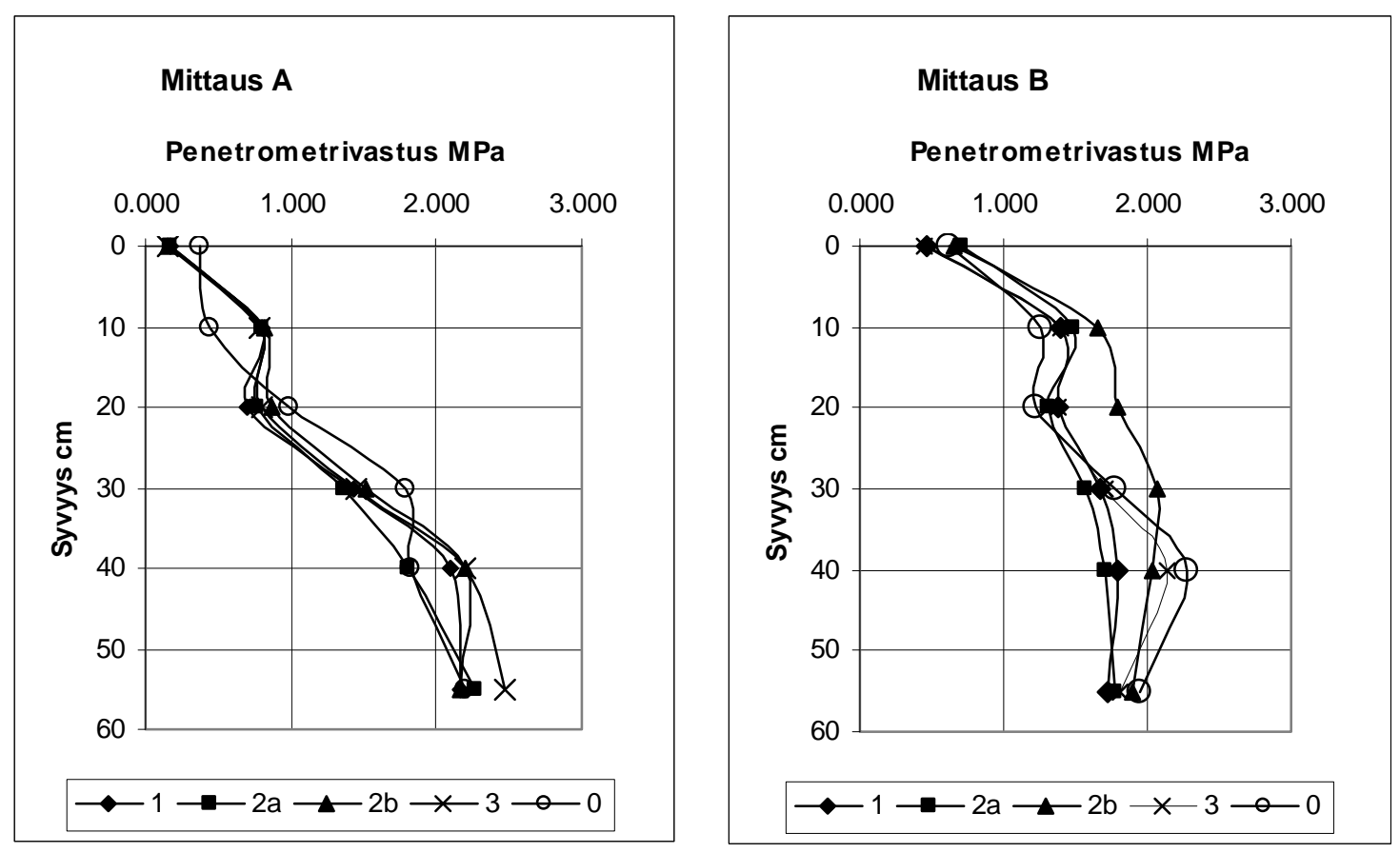

Kuva 1. Eri renkaiden (taulukko 1) aiheuttama savimaan penetrometrivastus 0-60 cm syvyydessä heti ajon jälkeen (mittaus A) ja vuoden kuluttua kokeen perustamisesta (mittaus B).

Maan pintakerroksen, 0-15 cm penetrometrivastus kasvoi selvästi ajon seurauksena mitattaessa heti ajon jälkeen, sen sijaan vuoden kuluttua vaikutus oli suhteellisesti vähäisempi (taulukko 2). Tiivistämättömässä koealassa näkyi vuoden aikana tapahtunut maan luontainen tiivistyminen $\mathrm{mm}$. sateen seurauksena. Tulos vastaa muita kerta-ajon jälkeen, sekä pelto- että laboratorio-oloista raportoituja mittaustuloksia (Kulli ym. 2003). Eroja eri renkaiden välillä heti ajon jälkeen ei ollut, mutta vuoden kuluttua oli keskiarvoissa havaittavissa selvät erot.

Taulukko 2. Penetrometrivastus (MPa) 0-15 cm kerroksessa renkaiden urissa sekä tiivistämättömässä (0) maassa heti ajon jälkeen (mittaus A) ja vuoden kuluttua (mittaus B)

\begin{tabular}{lrrrrr}
\hline Rengas & 1 & $2 \mathrm{a}$ & $2 \mathrm{~b}$ & 3 & 0 \\
\hline Mittaus A & 0.65 & 0.66 & 0.72 & 0.67 & 0.40 \\
Mittaus B & 1.18 & 1.27 & 1.27 & 1.19 & 1.04
\end{tabular}

\section{Johtopäätökset}

Mittaustulosten mukaan pellon pintakerros tiivistyy merkittävästi yhden ajokerran jälkeen n. 5-15 cm:n syvyydessä uran alapuolella. Maan pintakerroksen tiivistyessä kasvien kasvulle välttämätön muru- ja huokosrakenne rikkoontuu ja maassa tapahtuva veden, ravinteiden ja kaasujen kulkeutuminen vaikeutuu. Kun maata ei muokata ennen kasvuston perustamista, ajourat voivat haitata merkittävästi kasvien kasvua ja ravinteiden ottoa.

Kudosrakenteen ja rengaspaineen vaikutus maan tiivistymisessä näkyi selvästi vuoden kuluttua ajosta tehdyssä mittauksessa. Suurella (200 kPa) rengaspaineella vyörengas tiivisti maata eniten. Suuri rengaspaine pienentää maan ja renkaan välistä kosketusalaa vyörenkaalla ja pintapaine aiheuttaa maan pakkautumisen pehmeissä olosuhteissa tiivistymäksi. Alhaisella renkaan pintapaineella voidaan maan tiivistymisriskiä vähentää merkittävästi (Tijink ym. 1995). 


\section{Kirjallisuus}

Alakukku, L. 2000. Response of annual crops to subsoil compaction in a field experiment on clay soil lasting 17 years. Advances in Geoecology 32: 205-208.

Alakukku, L., Weisskopf, P., Chamen, W.C.T. Tijink, F.G.J., Van der Linden, J.P., Pires, S., Sommer, C., Spoor, G. 2003. Prevention strategies for field traffic-included subsoil compaction: a review, Part 1.Machine/soil interactions. Soil \& Tillage Research 73: 145-160.

Chamen, T., Alakukku, L., Pires, S., Sommer, C., Spoor, G., Tijink, F., Weisskopf, P. 2003. Prevention strategies for field traffic-induced subsoil compaction : a review, Part 2.Equipment and field practices. Soil \& Tillage Research 73: 161-174.

Håkansson, I. 2005. Machinery-induced compaction of arable soils. Incidence - consequences - counter-meas ures. SLU, Reports from the Division of Soil Management, No 109: 1-153

Kulli, B., Gysi, M., Fluhler, H. 2003. Visualizing soil compaction based on flow pattern analysis. Soil \& Tillage Research 70:29-40.

McAllister, M. 1983. Reduction in Rolling Resistance of tyres for Trailed Agricultural machinery. Journal of agricultural engineering Research 28:127-137

Tijink. F.G.J., Döll, G.D., Vermeulen, G.D. 1995. Technical and economic feasibility of low ground pressure running gear. Soil and Tillage Research 35: 99-110 